\title{
PRIMENA PROŠIRENE STVARNOSTI ZA UREĐIVANJE ENTERIJERA NA ANDROID MOBILNIM UREĐAJIMA
}

\section{AUGMENTED REALITY FOR INTERIOR DESIGN ON ANDROID MOBILE DEVICES}

\section{David Danji, Fakultet tehničkih nauka, Novi Sad}

\section{Oblast - ARHITEKTURA}

Kratak sadržaj - Ovaj rad opisuje teorijske osnove proširene stvarnosti kao i njenu primenu za uređivanje enterijera na Android mobilnim uređajima. Sa proširenom stvarnošću generišu se virtuelne elemente u stvarni svet pomoću digitalnih uređaja i time se dobija proširena slika stvarnog sveta. Cilj master rada je izrada aplikacije za Android mobilnu platformu koja pomoću kamere $i$ proširene stvarnosti korisniku omogućuje dodavanje $i$ vizualizaciju trodimenzionalnih modela arhitektonskih objekata u stvarni prostor. Aplikacija je izrađena pomoću programa Unity sa programskim dodacima Vuforia $i$ ARCore.

Ključne reči: $A R$, proširena stvarnost, Unity, Vuforia, ARCore, Android, nameštaj, enterijer

\begin{abstract}
This paper describes the theoretical foundations of augmented reality and usage of augmented reality for interior design on Android mobile devices. With augmented reality, virtual elements are generated into the real world using digital devices and that represents an augmented image of the real world. The aim of the master's thesis is to create an application for the Android mobile platform that, using a camera and augmented reality, allows the user to add and visualize threedimensional models of architectural objects in real space. The application was created using the Unity program with the Vuforia and ARCore plug-ins.
\end{abstract}

Keywords: AR, augmented reality, Unity, Vuforia, ARCore, Android, furniture, interior

\section{UVOD}

Proširena stvarnost (engl. augmented reality) je tehnologija koja dopunjuje fizički svet digitalnim elementima, koji ne postoje u stvarnom životu. Za razliku od virtu-elne stvarnosti, koja stvara potpuno virtuelno okruženje, sa proširenom stvarnošću generišu se virtuelni elementi u stvarni svet pomoću digitalnih uređaja i time se dobija proširena slika stvarnog sveta [1].

Proširena stvarnost može biti prikazana pomoću raznih uređaja, kao što su pametne naočari ili mobilni uređaji. Upotrebljava se u raznim područjima: u obrazovanju, marketingu, turizmu, za vojne potrebe, za video igre, $\mathrm{u}$ medicini, arhitekturi itd. [2].

\section{NAPOMENA:}

Ovaj rad proistekao je iz master rada čiji mentor je bila dr Vesna Stojaković, vanr.prof.
Aplikacije proširene stvarnosti kreću se od jednostavnih poput tekstualna obaveštenja, do složenih kao što su uputstva tokom hirurške operacije.

Cilj master rada je izrada aplikacije za Android mobilnu platformu koja pomoću kamere i proširene stvarnosti korisniku omogućuje dodavanje i vizualizaciju 3D modela arhitektonskih objekata u stvarni prostor. Okruženje Unity sa dodacima kao što su Vuforia ili ARCore, omogućuje razvoj ovakve aplikacije. Glavni razlog razvoja ove aplikacije jeste, da korisnici vide da li se neki komad nameštaja uklapa $\mathrm{u}$ ostatak enterijera, pre kupovine $\mathrm{i}$ bez odlaska u prodavnicu.

\section{PROŠIRENA STVARNOST}

U proširenoj stvarnosti, koriste se senzori, algoritmi i orijentacije kamere za crtanje 3D digitalnih elemenata posmatranih iz vidnog polja kamere u stvarni svet. Važno je napomenuti da se proširena stvarnost odnosi na sva ljudska čula, pa tako digitalni elementi mogu biti u obliku teksta, slika, zvuka, video zapisa, 3D modela i slično.

\subsection{Uređaji za proširenu stvarnost}

Glavne komponente uređaja za proširenu stvarnost su: 1. Kamere i senzori - prikupljaju podatke o interakcijama korisnika i šalju ih na obradu. Kamere na uređajima skeniraju okolinu i pomoću tih informacija uređaj locira fizičke objekte i generiše 3D modele. 2. Sistemi za obradu podataka - uređaji proširene stvarnosti treba da funkcionišu kao računari, zbog toga je potrebno da poseduju komponente kao što su: procesori, grafičke kartice, RAM memorije, WiFi, GPS, itd. Navedene komponente obrađuju sve ulazne podatke. 3. Izlazni uređaji - odnosi se na uređaje poput ekrana i zvučnika koje prenose informacije korisniku. 4. Refleksija - neki uređaji proširene stvarnosti koriste ogledala koja pomažu ljudskim očima da vide virtuelne slike [2].

Mnogi moderni uređaji već podržavaju proširenu stvarnost, od pametnih telefona i tableta do uređaja poput Google Glass-a, Microsoft HoloLens-a. Danas najpopularniji uređaji za proširenu stvarnost su mobilni uređaji (pametni telefoni, tableti). Većina pametnih telefona $\mathrm{i}$ tableta poseduju sve potrebne komponente za proširenu stvarnost, kao što su kamera, ekran, procesor, grafička kartica, akcelometar, žiroskop, GPS i audio senzori. Kamera smeštena na zadnjoj strani mobilnih uređaja prenosi sliku na ekran sa prednje strane i indirektno prikazuje korisniku svet preko ekrana. 


\subsection{Tipovi proširene stvarnosti}

Možemo razlikovati dva glavna tipa proširene stvarnosti: sa markerom i bez markera. Pored njih postoje još proširena stvarnost zasnovana na lokaciji i na projekciji. Glavni problem proširene stvarnosti jeste poravnanje i praćenje objekata, odnosno dobijanja položaja i orijentacije virtuelnog objekata u odnosu na položaj kamere $u$ stvarnom vremenu.

Različite vrste markera proširene stvarnosti su slike koje kamera može prepoznati i koristiti sa aplikacijom kao mesto za postavljanje virtuelnog objekta, odnosno aplikacija pokušava da prepozna predefinisane markere na slici koju snima kamera. Zatim, kada ga prepozna, algoritam izračunava poziciju i orijentaciju kamere u odnosu na marker. Na kraju, digitalni element se postavlja na poziciju markera. Markeri mogu biti bilo koji 3D ili 2D objekti koji su dovoljno veliki, imaju dovoljno detalja i jak kontrast.

Metoda detekcije bez markera oslanja se na informacije prikupljene kamerom uređaja, akcelometrom, žiroskopom i magnetometrom, koji izračunavaju poziciju kamere i tako omogućavaju upotrebu svih delova fizičkog okruže-nja kao mesto za postavljanje virtuelnog objekta. Nakon detekcije korisnik može detaljnije iz različitih uglova da gleda virtuelni objekat. Velika prednost ove metode je ta što za detekciju nije potrebno koristiti unapred definisani fizički marker, detekcija se može izvršiti bilo gde i bilo kada.

\subsection{Programski alati za proširenu stvarnost}

Pošto je cilj rada da se napravi mobilna aplikacija koja omogućuje korisnicima vizualizaciju 3D modela arhitektonskih objekata u stvarni prostor, odabran je Android mobilni operativni sistem zbog široke primene.

Aplikacije za proširenu stvarnost prolaze kroz četiri glavne faze kako bi dopunile stvarni svet digitalnim elementima: 1. Snimanje okoline - ulazni uređaji za proširenu stvarnost snimaju sliku stvarnog okruženja, odnosno fizičkog sveta. 2. Obrada slike - uređaj proširene stvarnosti obrađuje sliku kako bi odredio položaj postavljanja digitalnog elementa, odnosno računarski generisanog sadržaja. 3. Zahtev za potrebnim sadržajem - nakon što uređaj proširene stvarnosti odredi gde bi se mogli postavljati digitalni elementi, traži se njihovo postavljanje. 4. Superimpozicija - kada uređaj preuzme potreban sadržaj formira se konačna slika koja se sastoji od slike iz stvarnog okruženja i dodatnog virtuelnog sadržaja [3]. Jedan od programa koji omogućuju razvoj aplikacija za proširenu stvarnost je Unity, koji sadrži veliki broj programskih dodataka kao što su Vuforia i ARCore.

Unity omogućava razvoj visokokvalitetne 2D, 3D, VR (virtuelna stvarnost) i AR (proširena stvarnost) igara, animiranih filmova, arhitektonskih vizualizacija i aplikacija koje se mogu primeniti na više uređaja, uključujući mobilne uređaje, igračke konzole, računare itd. [2]. Unity je prvenstveno izabran jer ima veliku podršku za integraciju alata za proširenu stvarnost, odnosno ima pristup svim senzorima koji su potrebni za razvoj AR aplikacija.

Vuforia Engine je alat za kreiranje aplikacija proširene stvarnosti. Ovaj alat prepoznaje markere u stvarnom vremenu, koji mogu biti slike ili objekti. Na osnovu markera detektuje ravne površine, gde će 3D model biti postavljen. $\mathrm{Na}$ početku, kamera će započeti snimanje i šalje podatke, odnosno slike uređaju. Zatim, Aplikacija na uređaju pretra- žuje svaki piksel videa tražeći unapred definisani marker. Kada je marker detektovan, algoritmi će izračunati relativnu poziciju kamere u odnosu na marker. Nakon toga, iscrtava se virtuelni objekat na poziciju markera. Konačni prikaz se iscrtava na ekranu, a korisnik će na zaslonu videti kombinaciju digitalnog elementa i stvarnog sveta.

ARCore je alat za razvoj softvera koji koristi kameru koja se nalazi u mobilnom uređaju sa senzorima kako bi omogućio prikaz proširene stvarnosti. Glavni senzori koje ARCore koristi su akcelometar, žiroskop i magnetometar. Ovaj alat koristi tri ključne mogućnosti za integraciju virtuelnog sadržaja sa stvarnim svetom: 1. Kombinacijom praćenja interesnih tačaka $\mathrm{i}$ očitavanja sa inercijalnih senzora telefona, ARCore određuje položaj i orijentaciju uređaja u odnosu na fizički svet. Praćenje pokreta omogućuje korisniku da gleda objekte kroz ekran iz bilo kog ugla. 2 . Razumevanje okoline - omogućuje mobil-nom uređaju da detektuje veličinu i lokaciju horizontalnih i vertikalnih površina, poput zemlje ili zidova. 3. Procena svetlosti omogućuje uređaju da procenjuje osvetljenje u stvarnom svetu i da prilagođava boju i intenzitet svetlosti virtuelnih objekata kako bi oni izgledali što realističnije [4].

\subsection{Primena proširene stvarnosti u arhitekturi}

Proširena stvarnost $\mathrm{u}$ arhitektonskim projektima omogućuje postavljanje 3D modela predloženog dizajna u postojeći prostor pomoću mobilnih uređaja. Korisnici koji koriste ovakve aplikacije imaju mogućnost da vide kako će neki njihov projekat (zgrada, enterijer, most) izgledati u stvarnosti, na tom mestu gde će se izraditi. Jedna od primene proširene stvarnosti u arhitekturi je dizajn enterijera. Najpoznatija aplikacija za dizajn enterijera jeste IKEA Place, koja omogućuje korisnicima da isprobaju kako bi neki nameštaj iz IKEA prodavnice izgledao $\mathrm{u}$ stvarnom prostoru, pre njegove kupovine, slika 1.. Ovako kupci mogu bolje proceniti, kako se određeni proizvod uklapa u njihov enterijer. Zahvaljujući ovoj aplikaciji IKEA je povećala prodaju za $35 \%$ [5].

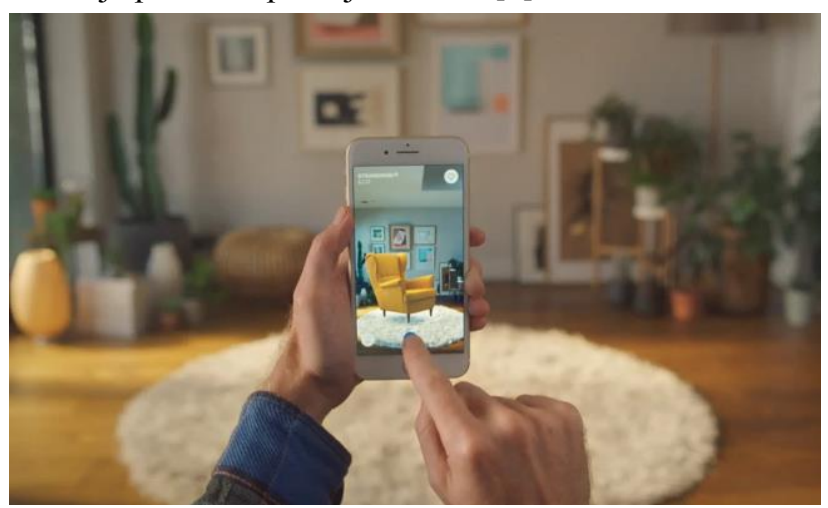

Slika 1. Mobilna aplikacija IKEA Place [5]

\section{IZRADA APLIKACIJE}

Za izradu aplikacije proširene stvarnosti za dizajn enterijera je korišćen programski alat Unity sa dodacima Vuforia i ARCore. Prvi korak jeste detekcija ravne površine i praćenje položaja virtuelnog objekta. Vuforia detektuje markere pomoću kamere, dok ARCore detektuje horizontalne i vertikalne površine pomoću senzora i kamere. Pošto se ovaj rad fokusira na Android uređaje, treba uzeti u obzir da samo određeni uređaji podržavaju ARCore. U radu se istražuje kakve su mogućnosti kada 
korisnik želi da isproba kako bi neki nameštaj izgledao u enterijeru: kada mobilni uređaj podržava ARCore, a u drugom slučaju kada mobilni uređaj ne podržava takve senzore.

\subsection{Rad sa programskim alatom Vuforia}

Vuforia ima u ponudi nekoliko vrsta markera za prepoznavanje i praćenje, koje možemo koristiti u radu. U ovom radu su korišćena tri metoda za prepoznavanje markera: 2D markeri (slike), 3D markeri (objekti) i tzv. korisnički definisane slike (engl. user defined), gde 2D marker nije predefinisan, nego korisnik može pomoću kamere da definiše 2D marker u stvarnom vremenu.

Markeri mogu da budu bilo koji objekti, sa tim da je potrebno da na njima bude puno detalja i jak kontrast. U programu Unity potrebno je dodati AR kameru, koja je glavna komponenta Vuforia-e i podlogu koja omogućuje korišćenje određenog markera, slika 2. Na kraju, potrebno je uči-tati 3D model nameštaja na podlogu, kao „,dete”.

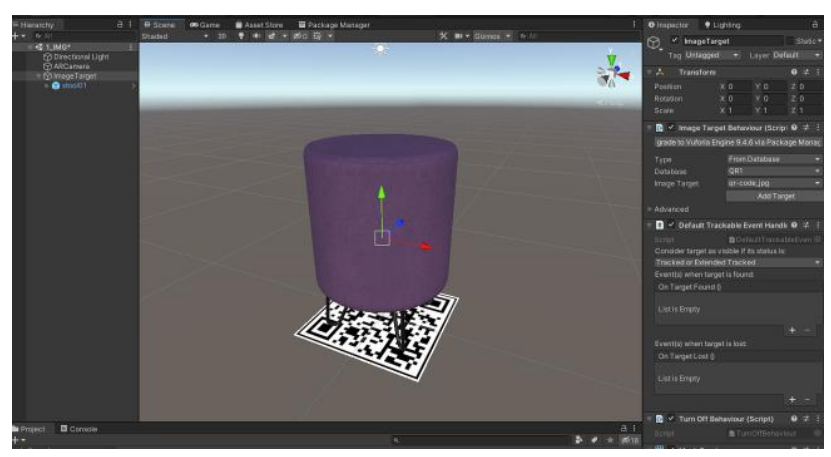

Slika 2. Scena u Unity-u sa 2D markerom

\subsection{Rad sa programskim alatom ARCore}

ARCore koristi objekte iz stvarnog sveta kao markere, odnosno pomoću senzora i kamere mobilnog uređaja detektuje horizontalne i vertikalne površine u stvarnom svetu. Korisnik u ovom slučaju prvo treba da skenira prostor sa laganim pomeranjem mobilnog uređaja. Svaka mala promena generiše novu tačku koju uređaj pamti. Pomoću skupa interesnih tačaka stvaraju se virtuelne mreže koje predstavljaju ravne površine.

Klikom na ovu mrežu učitava se 3D model nameštaja, tačno tamo gde je korisnik pritisnuo ekran na mobilnom uređaju. Nakon učitavanja korisnik može da pravi interakcije sa 3D modelom, da se približi 3D modelu i da ga gleda iz različitih uglova.

U programu Unity potrebno je dodati komponentu $A R$ Session koja kontroliše ceo proces proširene stvarnosti na uređaju, komponentu AR Session Origin koja transformiše ravne površine i tačke interesa u njihov krajnji položaj, orijentaciju i veličinu u aplikaciji i komponentu AR point cloud manager koja generiše oblak tačaka, odnosno skup interesnih tačaka.

Skripta AR Raycast Manager detektuje gde je korisnik kliknuo na ekran uređaja, tako što se pušta nevidljiva linija (zrak), od kamere do ravne površine. Nakon toga potrebno je programirati skriptu koja generiše horizontalne i vertikalne površine, na osnovu oblaka tačaka.

Ravne površine u enterijeru, koje se mogu detektovati, najčešće su zidovi, podovi, stolovi itd. slika 3.

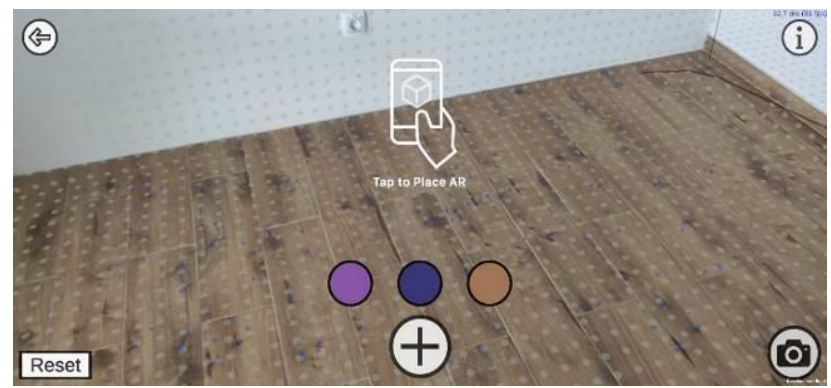

Slika 3. Prikaz virtuelnih mreža u aplikaciji

\subsection{Vizualizacija virtuelnog nameštaja}

Glavni cilj aplikacije proširene stvarnosti jeste koliko će realistično prikazivati virtuelne objekte u postojeće okruženje. Kvalitet prikaza slike je značajan u aplikacijama proširene stvarnosti za dizajniranje enterijera, kako bi korisnik imao osećaj da se virtuelni nameštaj nalazi u stvarnom svetu. Visok vizualni kvalitet može se postići PBR materijalima, osvetljenjem, senkama i okluzijom.

Materijali igraju ključnu ulogu u tome kako će neki objekat izgledati. Sa materijalima je moguće dobiti razne efekte poput reflektujuće ili hrapave površine na objektu. PBR (engl. Physically Based Rendering) je metoda senčenja i renderinga, koja pruža precizniji prikaz interakcije svetlosti sa površinom.

Virtuelne objekte je potrebno osvetliti u programu Unity. Bez svetla objekti bi bili crni. U Unity-u postoje 4 vrste svetla: Directional, Spot, Point i Area. U aplikaciji sa markerima osvetljenje je urađeno približno, kakvo bi to moglo da bude u enterijerima, dok ARCore pomoću skripte automatski prepozna kakvo je osvetljenje u enterijeru, koji sa određenim algoritmima podešava intenzitet i boju svetlosti.

Takođe, ARCore omogućava kreiranje HDR mape u stvarnom vremenu. Sa njom se dobijaju realistične refleksije, kao i informacije o glavnom izvoru svetla. Kako bi senke nameštaja bile prikazane, u Unity-u potrebno je dodati jednu ravan, ispod virtuelnog objekta sa šejderom koji omogućava da ravan bude nevidljiva, osim senke koja pada na tu ravan.

U aplikaciji sa markerima, senka će se uvek prikazati tačno ispod nameštaja, pod pravim uglom, dok u aplikaciji bez markera pravac senke će se uklapati sa ostalim senkama u enterijeru, jer pozicija glavnog svetla je poznata.

U proširenoj stvarnosti okluzija je, kada se nalazi neki predmet u stvarnom svetu između kamere i virtuelnog objekta, odnosno kada se deo virtuelnog objekta ne vidi, jer ga fizički objekat zaklanja.

Kod metode sa markerima ne postoji način da se uradi okluzija, jer Vuforia detektuje samo markere, i ne skenira prostor oko sebe, dok kod metode bez markera moguće je rešiti okluziju na osnovu detektovanih površina, pomoću šejdera, slika 4.

\section{KORISNIČKI INTERFEJS}

Korisnički interfejs u aplikacijama proširene stvarnosti zasnovan je na interakciji korisnika i uređaja sa ciljem poboljšanja ukupnog korisničkog iskustva i uživanja. Korisnički interfejs sadrži skup dugmića i instrukcija koje olakšavaju korisniku korišćenje aplikacije. 

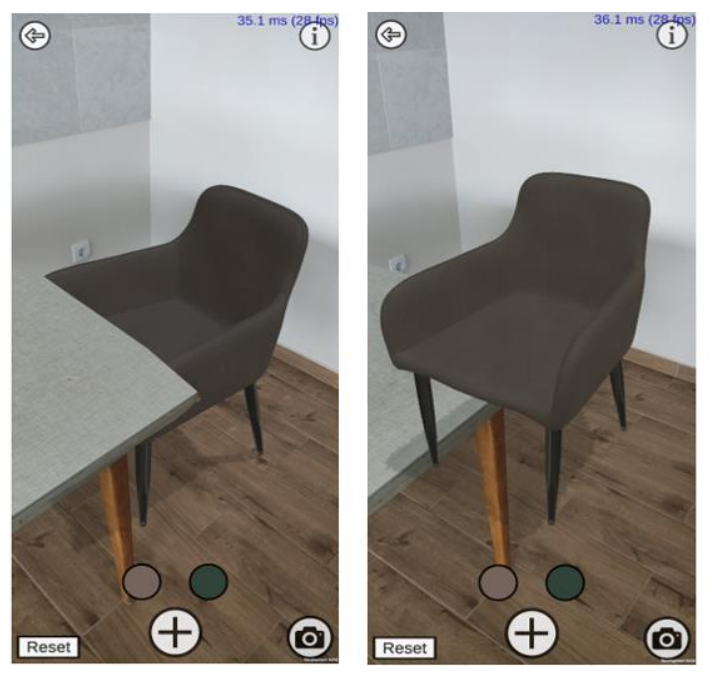

Slika 4. Virtuelni nameštaj sa i bez okluzije

Kod obe aplikacije urađen je isti korisnički interfejs, u kom se nalazi glavni meni sa dugmetom Start, koji pokreće aplikaciju, korisnička uputstva, biblioteka 3D nameštaja, dugme za snimanje ekrana, dugmići za menjanje boje nameštaja i drugi. Svako dugme je povezano sa određenom akcijom u Unity-u pomoću skripte. Aplikacija je dobila naziv „EnterijAR”.

\section{TESTIRANJE I REZULTATI}

Obe aplikacije (sa markerima i bez markera) su testirane na tri uređaja: Samsung Galaxy A50, Samsung Galaxy A40 i Xioami MI 9T. Testiranje aplikacije se vršilo u zatvorenom prostoru pri dnevnom i pri veštačkom svetlu. Takođe, aplikacija je testirana u u pejzažnim i portretnim prikazima. Prilikom testiranja, svaki uređaj je uspešno detektovao markere i ravne površine. Korisniku je omogućeno da pomera ili rotira virtuelne nameštaje, da odabere nameštaj iz biblioteke i da mu menja boju.

Veliki problem kod obe aplikacije predstavlja pregrejavanje mobilnih uređaja tokom korišćenje aplikacije, kao i brzo trošenje baterije. Problem može predstavljati i autofokus kamere, zbog čega markeri i površine neće biti detektovani ili će ih aplikacija pogrešno detektovati. Isti problem se javlja prilikom nedostatka svetla u enterijeru, kao i kada su površine previše reflektivne, prozirne ili nemaju puno detalja.

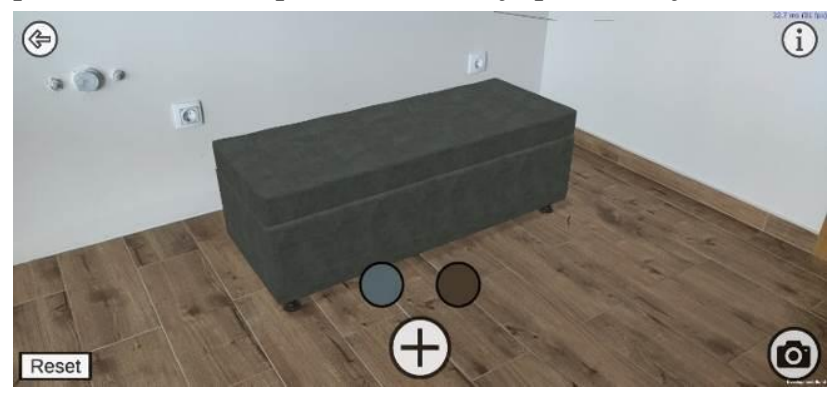

Slika 5. Virtuelni namě̌taj u enterijeru

\section{ZAKLJUČAK}

Primena proširene stvarnosti u arhitekturi omogućuje arhitektama lakše prezentovanje i razvijanje projekata, sa čim mogu da uštede vreme i novac.
Kroz ovaj rad razvijena je aplikacija koja omogućuje korisnicima da isprobaju da li će neki komad nameštaja uklapati u njihov enterijer. Neke od prednosti ove aplikacije su: korisnik može da isproba nameštaj bez kupovine i bez odlaska do prodavnice čime može da uštedi vreme, eliminisanje grešaka pri kupovini kao i smanjenje povrata nameštaja. Aplikacija koja radi na osnovu markera dostupan je velikom broju korisnika, dok je aplikacija bez markera dostupna manjem broju korisnika, jer senzore za ARCore podržava manji broj mobilnih uređaja.

Prednost metode sa markerima je ta što se detekcija i postavljanje nameštaja odvija brzo, dok sa metodom bez markera se to odvija sporije. Međutim, za korišćenje aplikacije sa markerima potreban je fizički objekat, odnosno fizički marker za detekciju, kako bi korisnik isprobao neki nameštaj u enterijeru.

Aplikaciju bez markera korisnik može da koristi bilo gde i bilo kad, jer mu nije potreban fizički marker. Takođe, ova aplikacija ima mogućnost da procenjuje svetlost $u$ enterijeru u kom se korisnik nalazi, što povećava kvalitet vizualizacije. Kod metode bez markera urađena je i okluzija.

U budućnosti, sa razvojem tehnologije može se očekivati da korisnik više neće moći da razlikuje objekte iz stvarnog sveta i objekte koji su dodati pomoću proširene stvarnosti.

\section{LITERATURA}

[1] A kiterjesztett valóság lehetőségei az oktatásban, http://matchsz.inf.elte.hu/VVprojekt/MobilAReducation.pdf (pristupljeno u oktobru 2020.)

[2] What is Augmented Reality (AR) and How does it work, https://thinkmobiles.com/blog/what-is-augmented-reality/ (pristupljeno u oktobru 2020.)

[3] What Is Augmented Reality? - The Complete Guide, https://cyberpulse.info/what-is-augmented-reality-thecomplete-guide/ (pristupljeno u oktobru 2020.)

[4] ARCore overview,

https://developers.google.com/ar/discover (pristupljeno u oktobru 2020.)

[5] Say hej to IKEA Place, https://www.ikea.com/au/en/ customer-service/mobile-apps/say-hej-to-ikea-placepub1f8af050 (pristupljeno u oktobru 2020.)

\section{Kratka biografija:}

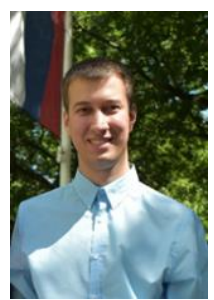

David Danji rođen je 1995. godine u Novom Sadu. Srednju elektrotehni-čku školu „Mihajlo Pupin” završio je 2014. godine u Novom Sadu. Završio je osnovne akademske studije Animacija u inženjerstvu 2019. godine na Fakultetu tehničkih nauka u Novom Sadu. Iste godine se upisao na master akademske studije Digitalne tehnike, dizajn i produkcija u arhitekturi i urbanizmu na istom fakultetu.

Kontakt: daviddanji95@gmail.com 